\title{
Implications for changes in Anopheles darlingi biting behaviour in three communities in the peri-Iquitos region of Amazonian Peru
}

\author{
Marta Moreno ${ }^{1 *}$, Marlon P Saavedra², Sara A Bickersmith ${ }^{3}$, William Lainhart ${ }^{4}$, Carlos Tong ${ }^{5}$, Freddy Alava ${ }^{6}$, \\ Joseph M Vinetz ${ }^{1,5}$ and Jan E Conn ${ }^{3,4}$
}

\begin{abstract}
Background: Malaria transmission in the peri-lquitos region of Amazonian Peru has been designated as seasonal and hypo-endemic with recently described hyper-endemic hotspots. Despite relatively recent distribution of long-lasting insecticidal bed nets (LLINs), malaria in Amazonian Peru persists and increased substantially in 2014 compared to previous years. Anopheles darlingi, identified as the main malaria vector, is known for its variable behaviour depending on locality and environment.

Methods: To evaluate vector biology metrics in relation to seasonality and malaria transmission, mosquito collections were carried out in three localities in the peri-lquitos region, Loreto, Peru in 2011-2012. Human landing catch (HLC) collection method, Shannon (SHA) and CDC trap types were compared for effectiveness in a neotropical setting. Abundance, human biting rate and entomological inoculation rate (EIR) were measured to provide an updated view of transmission patterns post-LLIN distribution.

Results: HLC collected significantly more anopheline mosquitoes than SHA and CDC light traps. Anopheles darlingi was the most prevalent species in all three villages (84\% overall). Biting patterns varied depending on trap type, season and village. EIR varied temporally (monthly) and spatially and the highest (2.52) occurred during the 2012 malaria outbreak in Cahuide. Unexpectedly there was a high infection rate (1.47 and 1.75) outside the normal malaria transmission season, coincident with a second local outbreak in Cahuide. The first identification of Anopheles dunhami and Anopheles oswaldoi C in Peru, using molecular markers, is also reported in this study.
\end{abstract}

Conclusion: These data underscore the importance of $\mathrm{HLC}$ as the most meaningful collection method for measuring vector biology indices in this region. The highest monthly EIR provides additional evidence of seasonal transmission in riverine localities correlated with high river levels, and An. darlingi as the only contributor to transmission. The trend of an increase in outdoor-biting together with early-evening infected mosquitoes may undermine the effectiveness of LLINs as a primary malaria intervention.

Keywords: Malaria, Anopheles darlingi, Entomological inoculation rate, Human landing catch, Amazonian Peru

\section{Background}

Dynamics, behaviour and host preference of anopheline species significantly affect malaria transmission in endemic areas. To elucidate the unique factors associated

\footnotetext{
*Correspondence: mmorenoleirana@ucsd.edu

1 Division of Infectious Diseases, Department of Medicine, University of California San Diego, La Jolla, CA, USA

Full list of author information is available at the end of the article
}

with maintenance in low or seasonal malaria transmission regions, such as the Amazon, entomological longitudinal studies that take into account seasonal and between-year variations are particularly informative for predictive models [1, 2]. The Peruvian Amazon has been defined as a low transmission area [3], with marked seasonal transmission, i.e., increased case numbers during the rainy season, from January to June, and low numbers during the dry season. However, newly described 
hyper-endemic foci linked to occupational activities [4] suggest considerable spatial variation in endemicity levels with important implications for epidemiology and efforts to reduce human-vector contact. During the past 4 years (from 11,779 in 2011 to 60,186 in 2014) there has been an annual increase in malaria cases in Loreto Department, Amazonian Peru. The proportion of malaria cases in Loreto is $93.69 \%$ of the whole country, and the annual parasite index is $58.49[5,6]$.

Anopheles darlingi is the main vector in the region although other species, such as Anopheles benarrochi s.l., may be involved in local transmission $[7,8]$. In the Iquitos area, Andean snowmelt combined with rainfall increases river levels (up to $10 \mathrm{~m}$ ), resulting in large seasonal fluctuations in anopheline abundance [9]. Taken together, these factors directly and indirectly affect malaria dynamics. Furthermore, in Amazonian Brazil, distinctive An. darlingi sub-populations have been shown to be adapted to distinctive rainfall regimes, likely promoting year-long transmission [10].

Anopheles darlingi's behaviour is extremely 'plastic' (exophagic/endophagic, exophilic/endophilic, opportunistic and highly anthropophilic), and it is difficult to extrapolate from one local epidemiological situation to another $[9,11,12]$. In Brazil, there is evidence of behavioural modification from endophily to exophily as a result of indoor insecticide spraying [13]. Peak biting activity varies depending on environmental variables, insecticide-treated nets (ITN) usage, and sociodemographic characteristics of the human population [14, 15]. Uni-, bi- and trimodal peaks have all been documented from different regions within the range of this species [12].

Entomological inoculation rate (EIR) is used to estimate intensities of malaria transmission and to evaluate the effectiveness of intervention strategies [16, 17]. However, comparisons of this metric across settings can be complicated by differences in sensitivity of sporozoite detection, time-scale and/or collection method. Direct dissection of salivary glands, ELISA assays and molecular techniques to detect Plasmodium DNA in the mosquito are the three most commonly used methods [18-20]. To date, infectivity rates of anophelines in the Peruvian Amazon have been based on ELISA [4, 9], and this technique could underestimate EIR because of decreased sensitivity compared to other molecular detection methods, such as PCR [21].

Considering the moderate to high levels of phenotypic and genetic variation in Amazonian An. darlingi populations [22-24], but see [25], this study hypothesizes that there will be high seasonal changes in human biting rate (HBR) and EIR within and among three malaria-endemic villages in the Iquitos area. Furthermore, because of the previously documented anthropophilic behaviour of $A n$. darlingi $[9,26]$ significantly more anophelines may be collected using human landing catch (HLC) than with other collection methods. This work can contribute to a better understanding of An. darlingi changes in behaviour vis-à-vis malaria transmission in response to vectorbased interventions such as long-lasting insecticide nets (LLINs).

\section{Methods \\ Collection sites}

A longitudinal study was designed to collect mosquitoes from three localities in the Iquitos area, Loreto Department, Peru during 2011-2012 (Figure 1). San José de Lupuna community (LUP) is a network of four villages located on the Nanay River, a tributary of the Amazon River, and the main occupation of the villagers includes agricultural activities such as mandioca cultivation and charcoal production. Villa del Buen Pastor (VBP) is on the Iquitos-Nauta road, $21 \mathrm{~km}$ south of Iquitos. Here, most inhabitants are involved in mixed crop farming and/or fishing. Cahuide (CAH) is a centre of palm roof production and is located where the Iquitos-Nauta road and the Itaya River intersect. Both Plasmodium vivax and Plasmodium falciparum cases are reported annually for all three villages. At the time of the field collections,

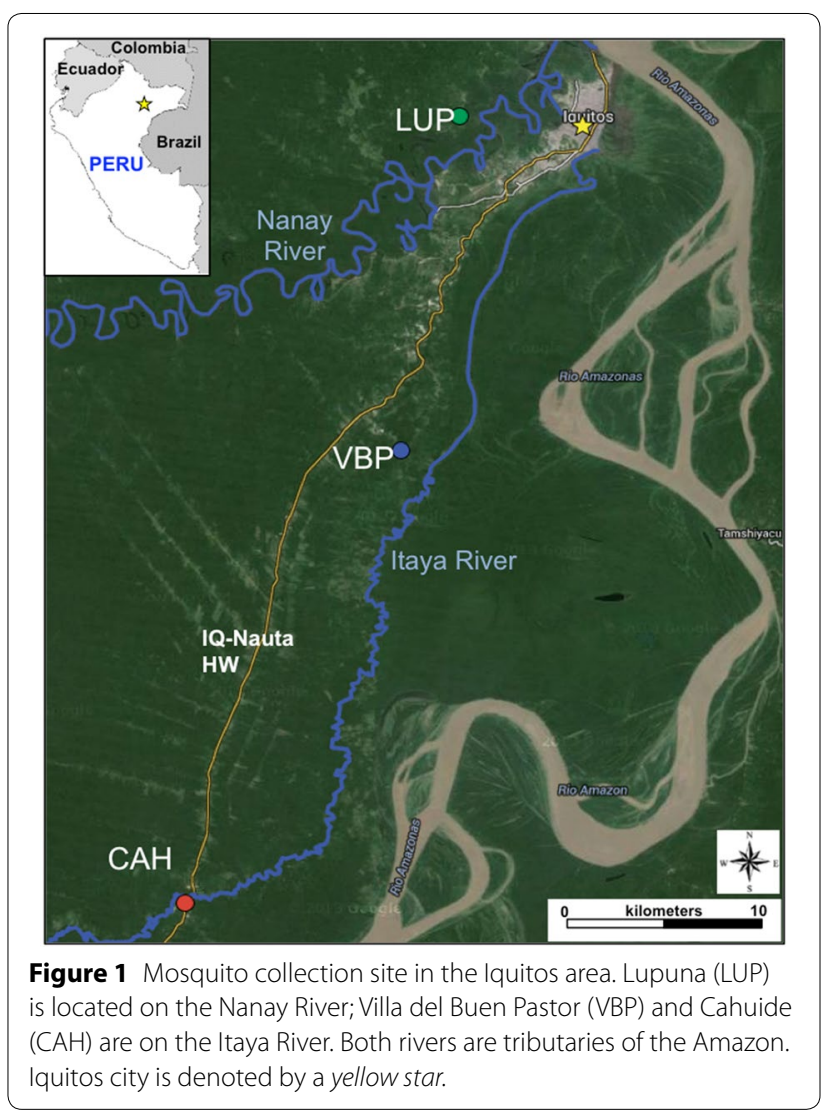


the only major intervention in the localities was the use of LLINs distributed during $2008-2010$ by the PAMAFRO initiative [27]. In 2012, after a local malaria outbreak, the Ministry of Health distributed new bed nets, and currently the inhabitants use either tocuyos (locally made cotton nets without insecticide) or LLINs (Table 1). Levels of the Nanay and Itaya rivers from 2011 to 2012 were obtained from Servicio Nacional de Meteorología e Hidrología del Perú [28].

\section{Collection methods}

Adult mosquitoes were collected during forty-eight nights in LUP, twenty-four in VBP and sixteen in CAH (four nights/month, every other month), including wet and dry season. HLC and Shannon trap (SHA) collections were performed outdoor for $12 \mathrm{~h}$ (18:00-06:00) stationed $\sim 10 \mathrm{~m}$ from the house with personnel rotating every $2 \mathrm{~h}$, to account for variation in individual attractiveness to mosquitoes [29]. CDC light traps were used for indoor collection and positioned next to the bed where a person slept under a LLIN. In addition, HLC indoor/ outdoor (18:00-22:00) was performed in LUP and CAH in 2012. HBR was calculated with the data obtained from $\mathrm{HLC}$ in the $12 \mathrm{~h}$ collection. Collected mosquitoes were separated by hour and then morphologically identified by trained personnel using the available keys [30-32]. Specimens were then individually stored in silica gel until DNA extraction.

\section{Laboratory processing}

\section{Circumsporozoite protein ELISA assays}

The head/thorax from specimens collected in LUP and CAH from 2012 were analysed in pools of five individuals (same species and same collection date/time). The ELISA protocol was performed following Wirtz et al. [18] and can distinguish among circumsporozoite protein (CSP) of $P$. falciparum and P. vivax (Pv210 and Pv247). Plasmodium falciparum sporozoite ELISA kit MRA-890 and $P$. vivax sporozoite ELISA kit MRA-1028K (deposited by R A Wirtz) were obtained through the Malaria Research and Reference Reagent Resource Center (MR4) as part

Table 1 Bed net coverage in Cahuide (CAH), Lupuna (LUP) and Villa Buen Pastor (VBP) in 2012

\begin{tabular}{llll}
\hline Locality & $\begin{array}{l}\text { House with bed } \\
\text { net }^{\mathbf{a}} \text { (\%) }\end{array}$ & $\begin{array}{l}\text { House with } \\
\text { LLIN (\%) }\end{array}$ & No. houses \\
\hline CAH & $276(99.6)$ & $125(45.1)$ & 277 \\
LUP & $211(100)$ & $185(87.7)$ & 211 \\
VBP & - & $56(100)^{b}$ & $63^{\mathrm{C}}$ \\
\hline
\end{tabular}

\footnotetext{
${ }^{a}$ Bed net includes LLIN and non-impregnated local bed nets.

b Number of houses and LLIN distribution in 2010.

c Number of houses in 2013.
}

of the BEI Resources Repository, NIAID, NIH and laboratory-reared female An. darlingi were used as negative controls. Optical density was measured at $410 \mathrm{~nm}$ in a Bio-Rad ELISA plate reader 30 and $60 \mathrm{~min}$ after adding the substrate. The cut-off for positivity was determined by the mean OD value of negative controls for each plate.

\section{DNA extraction and PCR assays}

Total genomic DNA was extracted from the head/thorax of each specimen from LUP and VBP collected in 2011 using the DNeasy tissue kit (Qiagen, CA, USA). A subsample of specimens that could not be identified morphologically (cryptic Nyssorhynchus species, damaged specimens, etc.) were identified using ITS2 sequence [33], ITS-RFLP [34] and the BOLD region of COI [35]. Plasmodium detection in mosquitoes was performed following the PCR-RFLP protocol described in Hasan et al. [20] based on the Plasmodium Cyt-b gene. Pools of five mosquitoes (same species and same date/time of capture) were tested together; individuals of each positive pool were tested individually. For both detection protocols, sporozoite rates were calculated using the number of positive mosquitoes for Plasmodium divided by the number of tested mosquitoes. Monthly EIR was calculated by multiplying the HBR by proportion of infected specimens per month.

\section{Ethical issues}

This study was approved by the Human Subjects Protection Program of the University of California San Diego, La Jolla, and by the Comité de Ética of the Universidad Peruana Cayetano Heredia and Asociación Benéfica PRISMA, Lima, Peru.

\section{Results}

A total of 14,001 female anophelines, 7,066 in LUP, 846 in VBP and 2,447 in $\mathrm{CAH}$, were collected in 48 sampling nights in LUP and VBP and 16 nights in CAH (summarized in Table 2). Anopheles darlingi was by far the most abundant anopheline in all three localities in each collection with a contribution by trap type varying in LUP from the lowest 33\% in December to the highest 96.4\% in June, and $88.9 \%$ in February to $100 \%$ in June in VBP and in nearly every collection in CAH. In LUP, Anopheles nuneztovari s.l. was collected during the most months of the year with up to $31.7 \%$ contribution to total mosquito abundance in February. Anopheles triannulatus s.l., Anopheles oswaldoi s.l. and An. benarrochi B were present in lower frequency and were collected primarily in February and April. In contrast, species composition was lower in VBP; An. darlingi was the most abundant species with the highest contribution in February (88.95\%) and the only species collected in June. Anopheles 
Table 2 Anopheles species composition in three localities in the Iquitos area in 2011-2013

\begin{tabular}{|c|c|c|c|c|}
\hline Locality & $\begin{array}{l}\text { Collection } \\
\text { month }\end{array}$ & $\begin{array}{l}\text { Anopheles species HLC } \\
\text { (total collected) }\end{array}$ & $\begin{array}{l}\text { Anopheles species SHA } \\
\text { (total collected) }\end{array}$ & $\begin{array}{l}\text { Species } \\
\text { composition (\%) }\end{array}$ \\
\hline \multirow[t]{31}{*}{ LUP 2011} & \multirow[t]{7}{*}{ February } & An. darlingi (327) & An. darlingi (17) & 57.1 \\
\hline & & An. nuneztovari s.l. (41) & An. nuneztovari s.l. (149) & 31.6 \\
\hline & & An. oswaldoi (2) & An oswaldoi (8) & 1.6 \\
\hline & & An. triannulatus (6) & An. triannulatus (12) & 3 \\
\hline & & An. benarrochi (1) & An. benarrochi (1) & 0.3 \\
\hline & & Nyssorhynchus (21) & Nyssorhynchus (8) & 4.8 \\
\hline & & Anopheles spp. (3) & Anopheles spp. (6) & 1.6 \\
\hline & \multirow[t]{7}{*}{ April } & An. darlingi $(2,381)$ & An. darlingi (430) & 82.7 \\
\hline & & An. nuneztovari s.l. (161) & An. nuneztovari s.l. (202) & 10.7 \\
\hline & & An. oswaldoi (22) & An. oswaldoi (42) & 1.9 \\
\hline & & An. triannulatus (3) & An. triannulatus (8) & 0.3 \\
\hline & & An. benarrochi (1) & An. benarrochi (1) & 0.05 \\
\hline & & Nyssorhynchus (85) & Nyssorhynchus (34) & 3.5 \\
\hline & & Anopheles spp. (22) & Anopheles spp. (6) & 0.85 \\
\hline & \multirow[t]{3}{*}{ June } & An. darlingi (107) & An. darlingi (26) & 96.4 \\
\hline & & An. oswaldoi (1) & & 0.7 \\
\hline & & Anopheles spp. (4) & & 2.9 \\
\hline & \multirow[t]{4}{*}{ August } & An. darlingi (30) & An. darlingi (3) & 86.84 \\
\hline & & An. oswaldoi (1) & & 2.6 \\
\hline & & Nyssorhynchus (2) & & 7.9 \\
\hline & & & Anopheles spp. (1) & 2.6 \\
\hline & \multirow[t]{5}{*}{ October } & An. darlingi (22) & An. darlingi (5) & 61.3 \\
\hline & & An. nuneztovari s.l. (5) & An. nuneztovari s.l. (1) & 13.6 \\
\hline & & An. oswaldoi (1) & An. oswaldoi (2) & 6.8 \\
\hline & & Nyssorhynchus (1) & & 2.2 \\
\hline & & Anopheles spp. (5) & Anopheles spp. (2) & 15.9 \\
\hline & \multirow[t]{5}{*}{ December } & An. darlingi (15) & An. darlingi (1) & 33.3 \\
\hline & & An. nuneztovari s.l. (4) & An. nuneztovari s.l. (1) & 10.4 \\
\hline & & An. oswaldoi (4) & An. oswaldoi (2) & 12.5 \\
\hline & & Nyssorhynchus (8) & Nyssorhynchus (3) & 22.9 \\
\hline & & Anopheles spp. (8) & Anopheles spp. (2) & 20.8 \\
\hline \multirow[t]{14}{*}{2012} & \multirow[t]{4}{*}{ February } & An. darlingi (379) & An. darlingi (4) & 93.2 \\
\hline & & An. oswaldoi (3) & & 0.7 \\
\hline & & Nyssorhynchus (8) & Nyssorhynchus (1) & 2.2 \\
\hline & & Anopheles spp. (16) & & 3.9 \\
\hline & \multirow[t]{2}{*}{ April } & An. darlingi (1353) & An. darlingi (300) & 99.9 \\
\hline & & Anopheles spp. (1) & & 0.1 \\
\hline & \multirow[t]{5}{*}{ June } & An. darlingi (499) & An. darlingi (151) & 96.6 \\
\hline & & An. oswaldoi (1) & An. oswaldoi (3) & 0.6 \\
\hline & & An. triannulatus (1) & Nyssorhynchus (2) & 0.2 \\
\hline & & Nyssorhynchus (12) & & 2 \\
\hline & & Anopheles spp. (4) & & 0.6 \\
\hline & August & An. darlingi (17) & An. darlingi (14) & 100 \\
\hline & September & An. darlingi (13) & An. darlingi (3) & 100 \\
\hline & November & An. darlingi (14) & & 100 \\
\hline \multirow[t]{2}{*}{ VBP 2011} & \multirow[t]{2}{*}{ February } & An. darlingi (1) & An. darlingi (7) & 88.9 \\
\hline & & An. rangeli (1) & & 11.1 \\
\hline
\end{tabular}


Table 2 continued

\begin{tabular}{|c|c|c|c|c|}
\hline Locality & $\begin{array}{l}\text { Collection } \\
\text { month }\end{array}$ & $\begin{array}{l}\text { Anopheles species HLC } \\
\text { (total collected) }\end{array}$ & $\begin{array}{l}\text { Anopheles species SHA } \\
\text { (total collected) }\end{array}$ & $\begin{array}{l}\text { Species } \\
\text { composition (\%) }\end{array}$ \\
\hline & \multirow[t]{4}{*}{ April } & An. darlingi (588) & An. darlingi (81) & 98.2 \\
\hline & & An. oswaldoi (3) & An. oswaldoi (1) & 0.57 \\
\hline & & Nyssorhynchus (2) & & 0.3 \\
\hline & & Anopheles spp. (1) & Anopheles spp. (5) & 0.89 \\
\hline & June & An. darlingi (50) & An. darlingi (3) & 100 \\
\hline & \multirow[t]{2}{*}{ August } & An. darlingi (41) & An. darlingi (7) & 98 \\
\hline & & Nyssorhynchus (1) & & 2 \\
\hline & \multirow[t]{2}{*}{ October } & An. darlingi (28) & An. darlingi (4) & 97 \\
\hline & & Nyssorhynchus (1) & & 3 \\
\hline & \multirow[t]{2}{*}{ December } & An. darlingi (16) & An. darlingi (4) & 95.2 \\
\hline & & Nyssorhynchus (1) & & 4.8 \\
\hline \multirow[t]{5}{*}{ CAH 2012} & \multirow[t]{2}{*}{ May } & An. darlingi (1653) & An. darlingi (543) & 99.3 \\
\hline & & Nyssorhynchus (16) & Nyssorhynchus (1) & 0.7 \\
\hline & August & An. darlingi (16) & An. darlingi (1) & 100 \\
\hline & October & An. darlingi (85) & - & 100 \\
\hline & December & An. darlingi (120) & An. darlingi (12) & 100 \\
\hline
\end{tabular}

Data in this table reflects the density of anopheline species present collected during the study. Collections were performed 4 days every month reported in the table; 2 days were performed $12 \mathrm{~h}$ (18.00-6.00) and 2 days were collected for $4 \mathrm{~h}$ (18.00-22.00).

Nyssorhynchus denotes specimens that could not be identified.

LUP Lupuna, VBP Villa Buen Pastor, CAH Cahuide, HLC human landing catch, SHA Shannon trap.

oswaldoi s.l. and Anopheles rangeli, the latter absent in LUP, were collected only in February and April. In CAH, of the specimens that were identified to species, only $A n$. darlingi was present.

Molecular identification was performed on a sub-sample of the specimens that could not be identified morphologically (Table 3). Anopheles nuneztovari s.l. has been identified from the Iquitos region previously [9]. However, because of the recognition of the Nuneztovari complex [36], which includes An. dunhami, An. nuneztovari s.s. and Anopheles goeldii, 22 samples were randomly tested using barcode $C O I$ sequences. All these samples were confirmed as An. dunhami using unique haplotypes with a bootstrap neighbour-joining Kimura 2-parameter (K2P) [37] distance model (1,000 replicates) and Bayesian phylogenetic tree analysis [38, 39] with published sequences [36, 40]. This confirmation of An. dunhami extends its distribution (previously known from Brazil and Colombia) into Amazonian Peru for the first time. In addition, the detection and confirmation of An. oswaldoi $\mathrm{C}$ in LUP and VBP is the first record of this species in the area. Anopheles benarrochi $\mathrm{B}$, a member of the An. benarrochi complex, was first reported in Peru recently [8].

Biting patterns were similar in LUP and VBP, regardless of collection method, in April 2011 (Figure 2). During the dry season, mosquito numbers were so low that comparisons of biting activity could not be done. In May 2012, for $\mathrm{CAH}$, there was a marked peak at 22:00 with HLC,
Table 3 Molecular identification of morphologically identified samples from LUP and VBP by different methods

\begin{tabular}{lccc}
\hline Locality & $\begin{array}{l}\text { Alul and BsrBI } \\
\text { digest }\end{array}$ & Barcode COI & ITS2 \\
\hline LUP & & & \\
An. nuneztovari s.l. & 252 & 22 & \\
An. dunhami & & 3 & 2 \\
An. benarrochi B & 3 & 1 & 3 \\
An. oswaldoi & 33 & 5 & 4 \\
An. oswaldoiC & & & \\
VBP & 1 & & \\
An. rangeli & 2 & 2 & \\
An. oswaldoi & & & \\
An. oswaldoiC & & &
\end{tabular}

Only An. darlingi was identified in CAH.

and 21:00 using SHA. Anopheline abundance using HLC and SHA in LUP and VBP (Figure 2) peaked sharply in April, and in May in CAH. Collection method and time was compared in each locality. Significance was detected in LUP only between 22:00 and 00:00 $(p<0.005)$. The same comparisons in VBP were only significant at 02:00 $(p<0.05)$. An independent analysis comparing dry versus rainy season could not be conducted due to low dry season specimen numbers. Overall, comparisons between collection methods in all localities were highly significant (Figure 3). 

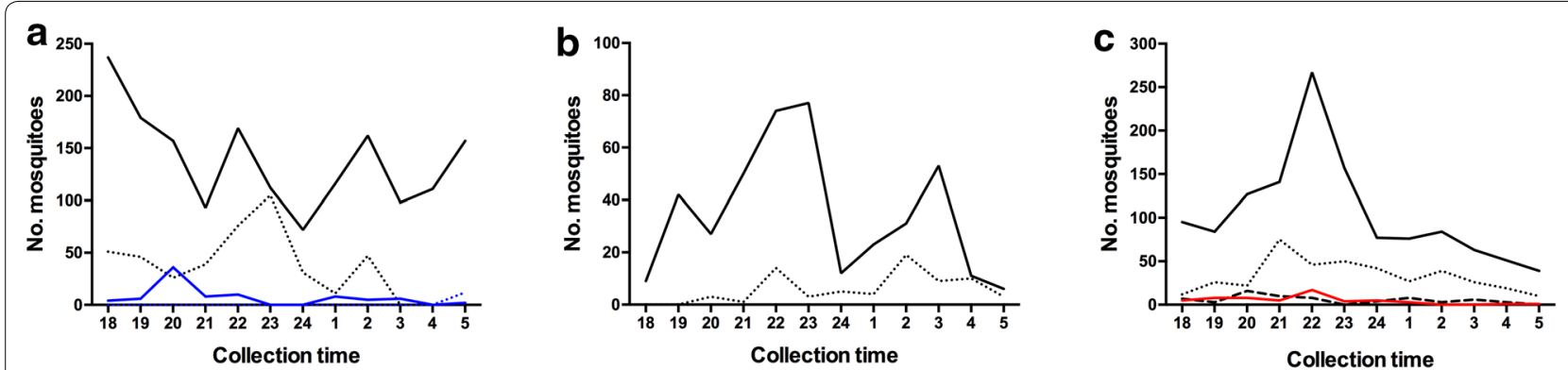

Figure 2 Mosquito collection by time and collection method in the three localities. a LUP: black line-HLC and black dotted-line-SHA, April 2011; blue line corresponds with HLC and blue dashed-line with SHA in February 2011. b VBP: black line-HLC; black dotted-line-SHA, April 2011. c CAH: black line-HLC and black dashed-line-SHA, May 2012. Red line: October 2012. Black dashed line: December 2012. Only months with positive Plasmodium mosquitoes are represented in each locality.
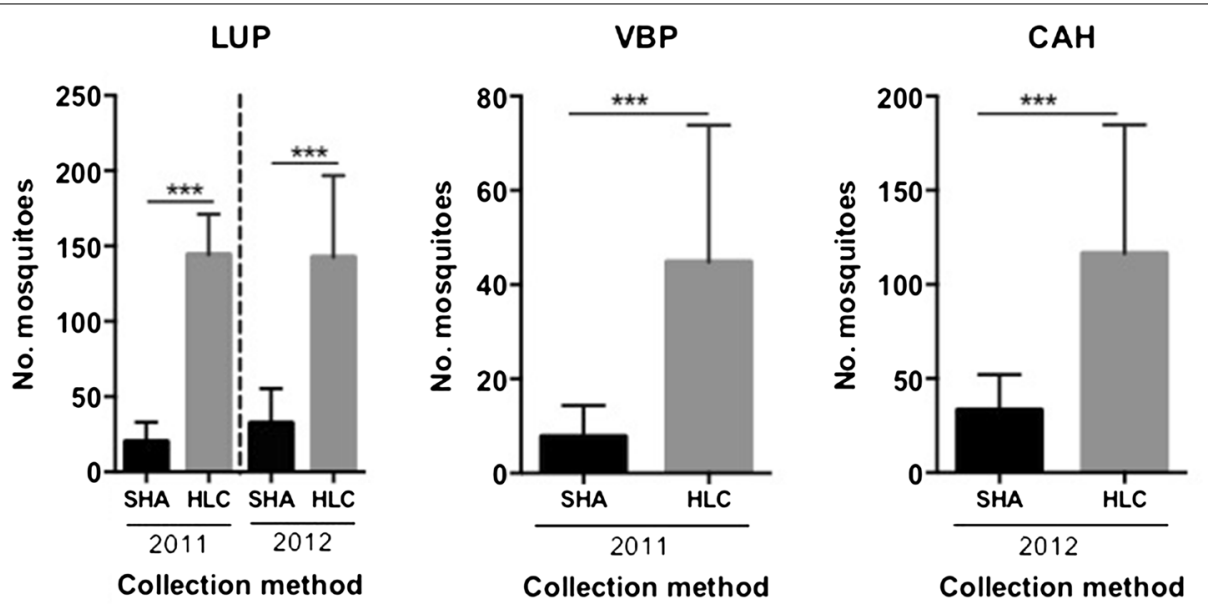

Figure 3 Mosquito captures by collection method and year of collections in the three study localities. Overall number of mosquitoes collected by HLC or SHA was statistically tested by non-parametric Wilcoxon-test; ${ }^{* *}$ significant value $p<0.001$.

Only 11 An. darlingi and four An. nuneztovari s.l. were collected with CDC traps indoors in LUP in April, the month with the greatest abundance of mosquitoes. In VBP and CAH no mosquitoes were collected with these traps, probably because of the characteristics of the houses (open windows and a gap between wall and roof).

In LUP, between $18: 00$ and $22: 00,82 \%$ of the mosquitoes were collected outdoors by HLC. More than $75 \%$ of these mosquitoes were $A n$. darlingi, followed by $7.8 \%$ An. nunezovari s.l., 2.2\% An. oswaldoi s.l. and 4.5\% Nyssorhynchus. All indoor specimens were $A n$. darlingi except one An. nuneztovari s.1. In CAH, 93.5\% were collected outdoors and all were identified as $A n$. darlingi. Statistical analysis of indoor versus peridomestic HLC (18.00-22.00) collections could not be done because of low numbers of indoor specimens.

HBR varied dramatically, clearly correlated with seasonality, in all localities (Figure 4). In LUP the overall anopheline peak was in April (HBR $=831$ bites/person/ night), mostly contributed by An. darlingi (HBR = 757).
In VBP, the highest HBR was also April $(\mathrm{HBR}=205)$ for $A n$. darlingi, with little variation when including the small number of other anopheline species. In $\mathrm{CAH}$, the highest HBR for An. darlingi (HBR $=630.5)$ was in May (collections were not done in April), decreasing to $\mathrm{HBR}=5$ in August. Pearson's correlation analysis between HBR and river levels confirmed the connection between these two parameters in LUP $(r=0.7182 ; p=0.0085)$ but not in CAH $(r=0.6214 ; p=0.3786)$ or in VBP $(r=0.7827$; $p=0.0657)$. The latter was likely non-significant due to the low number of observations (only from 2011), in contrast to two consecutive years of observations for LUP.

A total of 455 and 169 anopheline pools from LUP and VBP respectively, were tested for Plasmodium using Cyt$b$ and 25 of these (all $A n$. darlingi) were positive. In LUP, 13/2,275 (0.57\%) An. darlingi were infected with P. vivax; two were mixed infections with $P$. falciparum. In VBP, 12/845 (1.42\%) An. darlingi were infected with P. vivax, and four were mixed infections. Only two of the infected mosquitoes were collected by SHA, one in each of LUP 

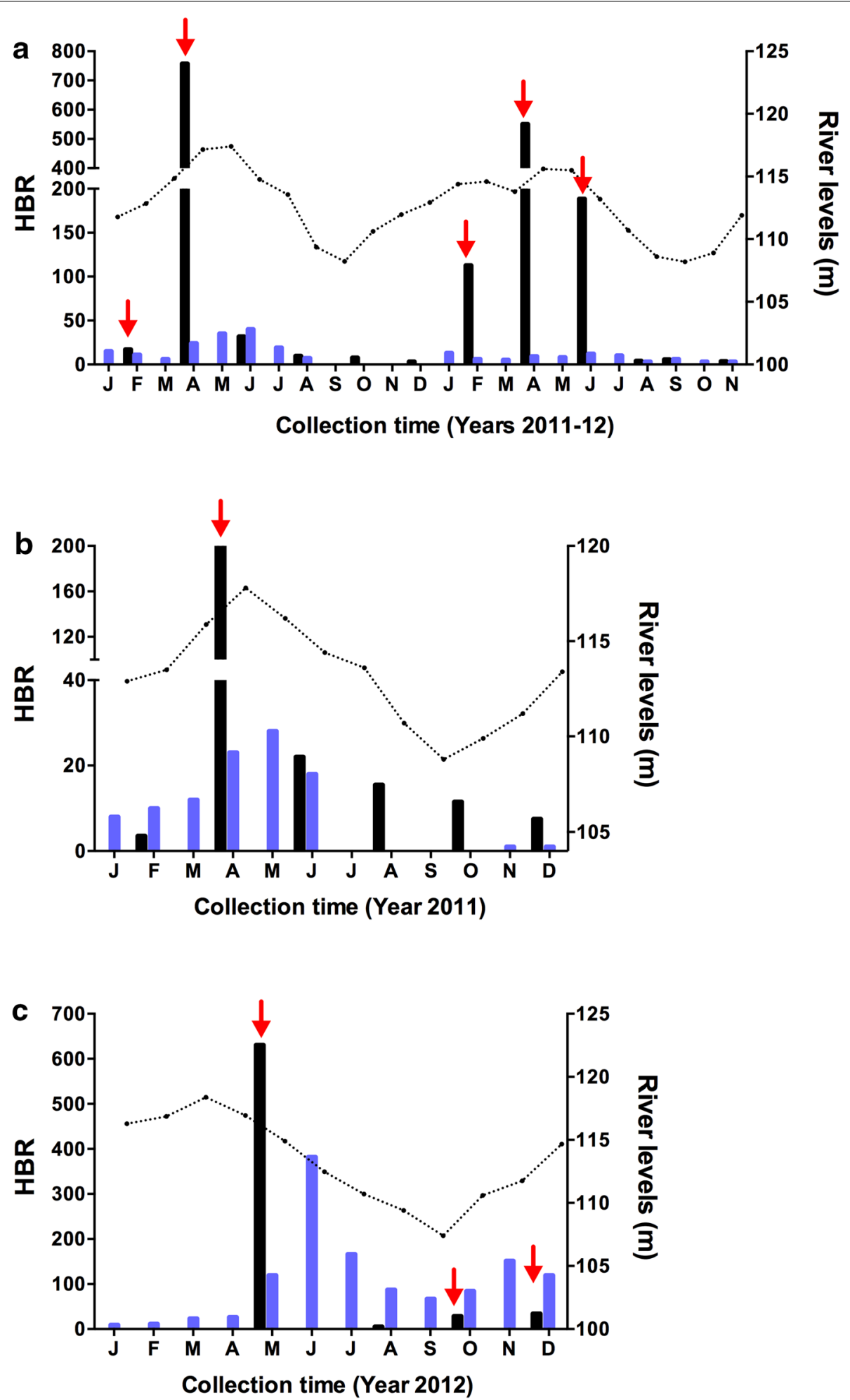

\section{HBR Malaria cases $\quad \cdots . . . \quad$ River levels $(m)$}

Figure 4 Human biting rate (bites/person/night), malaria cases and river levels (meters above sea level) in the three sites. Monthly Nanay River levels for a LUP (range 108.2-117.4 m) and b VBP; c CAH Itaya River levels (range 107.4-118.4 m). In both rivers, March-April were the maximum and September the minimum water levels. Malaria cases were diagnosed by microscopy and reported to the correspondent health post. Arrows represent Plasmodium-infected individual An. darlingi. 
and VBP. Infected mosquitoes were identified in the months of February and April in LUP in 2011, and February, April and June in 2012; in VBP, infective mosquitoes were detected only in April (Figure 4). The distribution of the infected $A n$. darlingi differed depending on locality and trap collection. Infected mosquitoes were detected from 18:00 to 03:00 in LUP and between 19:00 and 23:00 in VBP. None of the mosquitoes collected indoors (only from LUP and CAH) were infected (103 and 118 tested, respectively).

All samples from 2012 were tested by ELISA. These data showed that $9 / 558(0.32 \%$ IR) pools were positive in LUP and 18/496 (0.72\% IR) in CAH (all An. darlingi). In LUP, $P$. vivax VK247 was the most frequent variant followed by $P$. vivax VK210 and only one mosquito was infected with $P$. falciparum. In CAH, P. vivax VK210 was detected in 12 mosquitoes, $P$. vivax VK247 in seven and $P$. falciparum in three. The distribution of infected mosquitoes through the 12 -h collections varied by year and locality (Figure 4). In 2012 infected mosquitoes were detected earlier in the night than in 2011. All other Anopheles species were tested and were negative for Plasmodium. Therefore, EIR calculated only for An. darlingi, in LUP (2011) ranged from 0.04 in February to 0.80 in April. In VBP, EIR for April was 0.86 (Table 4). In 2012 in LUP EIR was higher than the previous year, i.e., 0.31 in February, 1.98 in April and 0.59 in June. In CAH, EIR was 2.52 in May, 0.33 and 0.25 in October and December, respectively (Table 4 ).

\section{Discussion}

EIR results demonstrated sustained seasonal malaria transmission among sites, ranging from 2.52 during the highest transmission season of April to 0 in the dry season. This rate is comparable to recent values for $A n$. darlingi in Amazonian Peru, Colombia and Venezuela [4, 43, 44]. The temporal anopheline density peak described in this study coincides with high river levels as previously reported [9]. The highest HBR was 757 bites/person/ night in LUP in April 2011 and 630.5 in CAH in May 2012. These values rank among the highest ever recorded for An. darlingi [12], for example, 837.7 in Matapi River (Amapa State, Brazil) [41], and 257.7 in Upper-Maroni (French Guiana) [42]. Because HBR is a major component of the EIR, such levels of HBR can be one indicator of the risk of contracting malaria, even when infection rate (IR) is low [41]. The IR levels detected in this study for $A n$. darlingi (Table 4) were comparable to others in the region, for example $0.1-3.1 \%$ in 1996-97, during a malaria outbreak [9] and a total of $1.4 \%$ among multiple sites along the Mazan River [4]. The highest IR in the present study was from LUP in February 2011 (5.88), however the number of mosquitoes was low (Table 2). Nevertheless, this IR was almost double the highest

Table 4 Anopheles darlingi human biting rate and entomological inoculation rate by month in the three localities studied

\begin{tabular}{|c|c|c|c|c|c|c|c|c|c|}
\hline \multirow[t]{2}{*}{ Collection date } & \multicolumn{3}{|l|}{ LUP } & \multicolumn{3}{|l|}{ VBP } & \multicolumn{3}{|l|}{$\mathrm{CAH}$} \\
\hline & IR $2011 / 2012$ & $\begin{array}{l}\text { HBR ( } \pm \text { SE) } \\
2011 / 2012\end{array}$ & EIR 2011/2012 & IR 2011 & HBR (土SE) 2011 & EIR 2011 & IR 2012 & HBR ( \pm SE) 2012 & EIR 2012 \\
\hline January & - & - & - & - & - & - & - & - & - \\
\hline February & $5.88 / 0.44$ & $\begin{array}{l}17( \pm 0.5) / 125.5 \\
\quad( \pm 9.5)\end{array}$ & $0.04 / 0.31$ & 0 & $3.5( \pm 0.5)$ & 0 & - & - & - \\
\hline March & - & - & - & - & - & - & - & - & - \\
\hline April & $0.66 / 0.54$ & $\begin{array}{l}757( \pm 83) / 550.5 \\
\quad( \pm 11.5)\end{array}$ & $0.807 / 1.98$ & 1.4 & $205( \pm 31)$ & 0.86 & - & - & - \\
\hline May & - & - & - & - & - & - & 1.26 & $630.5( \pm 201.5)$ & 2.52 \\
\hline June & $0 / 0.53$ & $\begin{array}{l}31.5( \pm 21.5) / 188.5 \\
\quad( \pm 126.5)\end{array}$ & 0/0.59 & 0 & $22( \pm 12)$ & 0 & - & - & - \\
\hline July & - & - & - & - & - & - & - & - & - \\
\hline August & 0 & $9.5( \pm 0.5) / 4( \pm 2)$ & $0 / 0$ & 0 & $15.5( \pm 3.5)$ & 0 & 0 & $5( \pm 2)$ & 0 \\
\hline September & & $-/ 5.5( \pm 1.5)$ & -10 & & & & & & \\
\hline October & 0 & $7.5( \pm 2.5) /-$ & $0 /-$ & 0 & $11.5( \pm 7)$ & 0 & 1.47 & $28.5( \pm 3.5)$ & 0.33 \\
\hline November & & $-/ 3.5( \pm 0.5)$ & -10 & & & & & & \\
\hline December & 0 & $4( \pm 1) /-$ & $0 /-$ & 0 & $7.5( \pm 0.5)$ & 0 & 1.75 & $34( \pm 4)$ & 0.25 \\
\hline
\end{tabular}

HBR: average bites per person per night (b/p/n) obtained from a mean of two collectors between 2 days/12 $\mathrm{h}$ per day per collection month. Calculations were made only with mosquitoes collected for $12 \mathrm{~h}$ by HLC.

IR infection rate, EIR entomological inoculation rate.

- Data not available. 
level reported by Parker and collaborators (2.88, Jan/Feb 2009). The high IR in CAH during the months of October and December (Table 4) coincides with an unexpected increase in reported local malaria cases (DIRESA, Peru Ministry of Health).

The lack of infected indoor An. darlingi captures suggests that most, if not all, malaria transmission in the study sites occurs outdoors (although there were few mosquitoes to test). This pattern of transmission possibly represents a shift in An. darlingi biting behaviour related to the use of LLINs. Data from 1996-97 detected nearly a 1:1 proportion of An. darlingi indoor:outdoor from three localities south of Iquitos [9], prior to any distribution of LLINs [27]. Although this study was not designed to test the hypothesis of shifting behaviour of $A n$. darlingi driven by LLINs, there are recent examples of such behaviour in Senegal for Anopheles funestus [45] and in the Solomon Islands for Anopheles farauti [46]. The results presented in this manuscript may presage a new trend in An. darlingi, and additional investigation should be performed.

The dominance of $A n$. darlingi compared to all other species in this study is evidence of its successful spread in both rural and urban areas surrounding Iquitos, with the apparent reduction of other anopheline species such as An. benarrochi s.l. and An. oswaldoi s.l. [9, 47]. Extension of activity of An. darlingi throughout the night, as demonstrated in this report, is related to high mosquito densities and has also been reported in Amazonian Brazil [48].

The molecular identification of An. dunhami suggests that previous studies that have identified An. nuneztovari s.s. in Loreto could be erroneous, since currently available morphological keys cannot distinguish between adult females of An. dunhami and An. nuneztovari [36]. Junin is the second most important department reporting malaria cases in Peru (2,038 in 2014). Anopheles trinkae, identified as the main malaria vector there [49], may be $A n$. dunhami [40]. If so, it would be important to determine the distribution and bionomics of An. dunhami in Peru, and to update current dichotomous keys to reflect its presence.

This study clearly showed that overall, in the Iquitos area, the HLC method caught an average of 35 times as many mosquitoes as the SHA, and CDC-LTs were not effective. Findings of significantly more infected mosquitoes collected with HLC compared with SHA agree with a recent review of anopheline collection methods conducted in Brazil [50], that determined that HLC is still the most efficient collection method. In the Neotropics few alternatives to HLC have been evaluated. Hiwat et al. [51] in Suriname compared HLC, CDC-LT, Mosquito Magnet Liberty Plus mosquito traps and BG sentinel traps baited with $\mathrm{CO}_{2}$ to collect $A n$. darlingi; HLC attracted significantly greater numbers of the target species. Additionally, HLC compared to Magnet Traps in Venezuela attracted significantly more An. darlingi [52]. In Brazil, the BGMalaria trap [53] was as effective as HLC with respect to number and parity of An. darlingi collected, and thus appears to be a promising alternative for collecting and monitoring this important vector. A new collection method, barrier screens, was highly successful in collecting blood-fed anopheline vectors in the South Pacific [54]. Future research activities in the peri-Iquitos region will test the efficacy of this method and expand its potential utility for calculating vector biology metrics, if warranted.

\section{Conclusions}

This study clearly demonstrated microgeographic differences in $A n$. darlingi peak biting times, biting patterns, infectivity, and EIR. Study sites presented moderate EIR at least once annually, coincident with the highest mosquito abundance, similar to EIR reported in hyperendemic transmission settings in the Amazon. Anopheles darlingi was the most abundant species and the only one infected with Plasmodium, confirming its importance as the major malaria vector in the area. HLC is still the most effective method for An. darlingi collection in this region.

\section{Authors' contributions}

MM designed the study, collected mosquitoes, identified specimens, analysed data and wrote the manuscript. MPS collected mosquitoes, identified specimens, performed ELISA and PCR and helped analyse data. SAB performed molecular identification of the specimens and Plasmodium detection, and helped write the manuscript. WL analysed data and helped write the manuscript. CT identified specimens and helped analysed data. FA provided information on bed-net use and distribution, malaria case data and details of study sites. JMV helped write the manuscript. JEC designed the study, analysed data and wrote the manuscript. All authors read and approved the final manuscript.

\section{Author details}

${ }^{1}$ Division of Infectious Diseases, Department of Medicine, University of California San Diego, La Jolla, CA, USA. ${ }^{2}$ Asociación Benéfica PRISMA, Lima, Peru. ${ }^{3}$ Wadsworth Center, New York State Department of Health, Albany, NY, USA. ${ }^{4}$ Department of Biomedical Sciences, School of Public Health, University at Albany (State University of New York), Albany, NY, USA. ${ }^{5}$ Instituto de Medicine Tropical "Alexander von Humboldt", Universidad Peruana Cayetano Heredia, Lima, Peru. ${ }^{6}$ Ministry of Health, Iquitos, Peru.

\section{Acknowledgements}

We thank all the people from the communities where mosquitoes were collected, and field workers Eliseo Ramirez, Jose Manuel Reyna, Victor Pacaya, David Arimuya, and Hercules Maytahuari. We appreciate the long-term collaboration with the Dirección Regional de Salud (DIRESA, lquitos, Loreto), especially to Dr Hugo Rodriguez; Dr Dionicia Gamboa and Dr Alejandro Llanos from Universidad Peruana Cayetano Heredia, Lima, Peru. This project was funded by US National Institutes of Health Cooperative Agreement U19AI089681 to JMV and NIH R01Al54139-02 to JEC.

\section{Compliance with ethical guidelines}

\section{Competing interests}

The authors declare that they have no competing interests. 
Received: 2 March 2015 Accepted: 10 July 2015

Published online: 30 July 2015

\section{References}

1. Kleinschmidt I, Sharp BL, Clarke GP, Curtis B, Fraser C (2001) Use of generalized linear mixed models in the spatial analysis of small-area malaria incidence rates in Kwazulu Natal, South Africa. Am J Epidemiol 153:1213-1221

2. Hirzel AH, Hausser J, Chessel D, Perrin N (2002) Ecological-niche factor analysis: how to compute habitat-suitability maps without absence data? Ecology 83:2027-2036

3. da Silva-Nunes M, Moreno M, Conn JE, Gamboa D, Abeles S, Vinetz JM et al (2012) Amazonian malaria: asymptomatic human reservoirs, diagnostic challenges, environmentally driven changes in mosquito vector populations, and the mandate for sustainable control strategies. Acta Trop 12:281-291

4. Parker BS, Paredes Olortegui M, Penataro Yori P, Escobedo K et al (2013) Hyperendemic malaria transmission in areas of occupation-related travel in the Peruvian Amazon. Malar J 12:178

5. Chowell G, Munayco CV, Escalante AA, McKenzie FE (2009) The spatial and temporal patterns of falciparum and vivax malaria in Peru: 19942006. Malar J 8:142

6. MINSA (2014) Ministerio de Salud del Perú: Sala de Situación de Salud

7. Flores-Mendoza C, Fernandez R, Escobedo-Vargas KS, Vela-Perez Q, Schoeler GB (2004) Natural Plasmodium infections in Anopheles darlingi and Anopheles benarrochi (Diptera: Culicidae) from eastern Peru. J Med Entomol 41:489-494

8. Conn JE, Moreno M, Saavedra M, Bickersmith SA, Knoll E, Fernandez R et al (2013) Molecular taxonomy of Anopheles (Nyssorhynchus) benarrochi (Diptera: Culicidae) and malaria epidemiology in southern Amazonian Peru. Am J Trop Med Hyg 88:319-324

9. Reinbold-Wasson DD, Sardelis MR, Jones JW, Watts DM, Fernandez R, Carbajal F et al (2012) Determinants of Anopheles seasonal distribution patterns across a forest to periurban gradient near lquitos. Peru. Am J Trop Med Hyg 86:459-463

10. Angella AF, Salgueiro P, Gil LH, Vicente JL, Pinto J, Ribolla PE (2014) Seasonal genetic partitioning in the neotropical malaria vector, Anopheles darlingi. Malar J 13:203

11. Zimmerman RH, Galardo AK, Lounibos LP, Arruda M, Wirtz R (2006) Bloodmeal hosts of Anopheles species (Diptera: Culicidae) in a malaria-endemic area of the Brazilian Amazon. J Med Entomol 43:947-956

12. Hiwat H, Bretas G (2011) Ecology of Anopheles darlingi Root with respect to vector importance: a review. Parasit Vectors 4:177

13. Gil LH, Alves FP, Zieler H, Salcedo JM, Durlacher RR, Cunha RP et al (2003) Seasonal malaria transmission and variation of anopheline density in two distinct endemic areas in Brazilian Amazonia. J Med Entomol 40:636-641

14. Moreno JE, Rubio-Palis Y, Paez E, Perez E, Sanchez V (2007) Abundance, biting behaviour and parous rate of anopheline mosquito species in relation to malaria incidence in gold-mining areas of southern Venezuela. Med Vet Entomol 21:339-349

15. Rodriguez M, Perez L, Caicedo JC, Prieto G, Arroyo JA, Kaur H et al (2009) Composition and biting activity of Anopheles (Diptera: Culicidae) in the Amazon region of Colombia. J Med Entomol 46:307-315

16. Martins-Campos KM, Pinheiro WD, Vitor-Silva S, Siqueira AM, Melo GC, Rodrigues IC et al (2012) Integrated vector management targeting Anopheles darlingi populations decreases malaria incidence in an unstable transmission area, in the rural Brazilian Amazon. Malar J 11:351

17. Athrey G, Hodges TK, Reddy MR, Overgaard HJ, Matias A, Ridl FC et al (2012) The effective population size of malaria mosquitoes: large impact of vector control. PLoS Genet 8:e1003097

18. Wirtz RA, Zavala F, Charoenvit Y, Campbell GH, Burkot TR, Schneider I et al (1987) Comparative testing of monoclonal antibodies against Plasmodium falciparum sporozoites for ELISA development. Bull World Health Organ 65:39-45

19. Snounou G, Viriyakosol S, Zhu XP, Jarra W, Pinheiro L, do Rosario VE et al (1993) High sensitivity of detection of human malaria parasites by the use of nested polymerase chain reaction. Mol Biochem Parasitol 61:315-320

20. Hasan AU, Suguri S, Sattabongkot J, Fujimoto C, Amakawa M, Harada M et al (2009) Implementation of a novel PCR based method for detecting malaria parasites from naturally infected mosquitoes in Papua New Guinea. Malar J 8:182

21. Povoa MM, Machado RL, Segura MN, Vianna GM, Vasconcelos AS, Conn JE (2000) Infectivity of malaria vector mosquitoes: correlation of positivity between ELISA and PCR-ELISA tests. Trans R Soc Trop Med Hyg 94:106-107

22. Manguin S, Wilkerson RC, Conn JE, Rubio-Palis Y, Danoff-Burg JA, Roberts DR (1999) Population structure of the primary malaria vector in South America, Anopheles darlingi, using isozyme, random amplified polymorphic DNA, internal transcribed spacer 2, and morphologic markers. Am J Trop Med Hyg 60:364-376

23. Santos LM, Gama RA, Eiras AE, Fonseca CG (2010) Genetic differences based on AFLP markers in the mosquito species Anopheles darlingi collected in versus near houses in the region of Porto Velho, RO, Brazil. Genet Mol Res 9:2254-2262

24. Mirabello L, Conn JE (2006) Molecular population genetics of the malaria vector Anopheles darlingi in Central and South America. Heredity (Edinb) 96:311-321

25. Pinedo-Cancino V, Sheen P, Tarazona-Santos E, Oswald WE, Jeri C, Vittor AY et al (2006) Limited diversity of Anopheles darlingi in the Peruvian Amazon region of lquitos. Am J Trop Med Hyg 75:238-245

26. Vittor AY, Gilman RH, Tielsch J, Glass G, Shields T, Sanches Lozano W et al (2006) The effect of deforestation on the human-biting rate of Anopheles darlingi, the primary vector of falciparum malaria in the Peruvian Amazon. Am J Trop Med Hyg 74:3-11

27. Rosas-Aguirre A, Guzman-Guzman M, Moreno-Gutierrez D, RodriguezFerrucci H, Vargas-Pacherrez D, Acuna-Gonzalez Y (2011) Long-lasting insecticide - treated bednet ownership, retention and usage 1 year after their distribution in Loreto, Peru. Rev Peru Med Exp Salud Publica 28:228-236 (in Spanish)

28. http://www.senamhi.gob.pe. Accessed 6 Nov 2014

29. Knols BG, de Jong R, Takken W (1995) Differential attractiveness of isolated humans to mosquitoes in Tanzania. Trans R Soc Trop Med Hyg 89:604-606

30. Forattini OP (1962) Entomologia Medica, vol 1. Faculdade de Higiene e Sáude Publica, São Paulo

31. Faran ME, Linthicum KJ (1981) A handbook of the Amazonian species of Anopheles (Nyssorhynchus) (Diptera: Culicidae). Mosquito System 13:1-81

32. Consoli RA, Lourenco-de-Oliveira R (1994) Principais mosquitos de importância sanitária no Brasil. Editora Fiocruz, Fundação Oswaldo Cruz

33. Zapata MA, Cienfuegos AV, Quiros Ol, Quinones ML, Luckhart S, Correa MM (2007) Discrimination of seven Anopheles species from San Pedro de Uraba, Antioquia, Colombia, by polymerase chain reaction-restriction fragment length polymorphism analysis of its sequences. Am J Trop Med Hyg 77:67-72

34. Matson R, Rios CT, Chavez CB, Gilman RH, Florin D, Sifuentes VL et al (2008) Improved molecular technique for the differentiation of neotropical anopheline species. Am J Trop Med Hyg 78:492-498

35. Folmer O, Black M, Hoeh W, Lutz R, Vrijenhoek R (1994) DNA primers for amplification of mitochondrial cytochrome c oxidase subunit I from diverse metazoan invertebrates. Mol Mar Biol Biotechnol 3:294-299

36. Foster PG, Bergo ES, Bourke BP, Oliveira TM, Nagaki SS, Sant'Ana DC et al (2013) Phylogenetic analysis and DNA-based species confirmation in Anopheles (Nyssorhynchus). PLoS One 8:e54063

37. Kimura M (1980) A simple method for estimating evolutionary rates of base substitutions through comparative studies of nucleotide sequences. J Mol Evol 16:111-120

38. Huelsenbeck JP, Ronquist F (2001) MRBAYES: Bayesian inference of phylogenetic trees. Bioinformatics 17:754-755

39. Ronquist F, Huelsenbeck JP (2003) MrBayes 3: Bayesian phylogenetic inference under mixed models. Bioinformatics 19:1572-1574

40. Ruiz F, Linton YM, Ponsonby DJ, Conn JE, Herrera M, Quinones ML et al (2010) Molecular comparison of topotypic specimens confirms Anopheles (Nyssorhynchus) dunhami Causey (Diptera: Culicidae) in the Colombian Amazon. Mem Inst Oswaldo Cruz 105:899-903

41. Galardo AK, Arruda M, D'Almeida Couto AA, Wirtz R, Lounibos LP, Zimmerman $\mathrm{RH}$ (2007) Malaria vector incrimination in three rural riverine villages in the Brazilian Amazon. Am J Trop Med Hyg 76:461-469

42. Girod R, Gaborit P, Carinci R, Issaly J, Fouque F (2008) Anopheles darlingi bionomics and transmission of Plasmodium falciparum, Plasmodium vivax 
and Plasmodium malariae in Amerindian villages of the Upper-Maroni Amazonian forest, French Guiana. Mem Inst Oswaldo Cruz 103:702-710

43. Rubio-Palis Y, Bevilacqua M, Medina DA, Moreno JE, Cardenas L, Sanchez $\checkmark$ et al (2013) Malaria entomological risk factors in relation to land cover in the Lower Caura River Basin, Venezuela. Mem Inst Oswaldo Cruz 108:220-228

44. Naranjo-Diaz N, Rosero DA, Rua-Uribe G, Luckhart S, Correa MM (2013) Abundance, behavior and entomological inoculation rates of anthropophilic anophelines from a primary Colombian malaria endemic area. Parasit Vectors 6:61

45. Sougoufara S, Diedhiou SM, Doucoure S, Diagne N, Sembene PM, Harry $\mathrm{M}$ et al (2014) Biting by Anopheles funestus in broad daylight after use of long-lasting insecticidal nets: a new challenge to malaria elimination. Malar J 13:125

46. Bugoro H, Iro'ofa C, Mackenzie DO, Apairamo A, Hevalao W, Corcoran S et al (2011) Changes in vector species composition and current vector biology and behaviour will favour malaria elimination in Santa Isabel Province, Solomon Islands. Malar J 10:287

47. Schoeler GB, Flores-Mendoza C, Fernandez R, Davila JR, Zyzak M (2003) Geographical distribution of Anopheles darlingi in the Amazon Basin region of Peru. J Am Mosq Control Assoc 19:286-296

48. Moutinho PR, Gil LH, Cruz RB, Ribolla PE (2011) Population dynamics, structure and behavior of Anopheles darlingi in a rural settlement in the Amazon rainforest of Acre, Brazil. Malar J 10:174
49. Hayes J, Calderon G, Falcon R, Zambrano V (1987) Newly incriminated anopheline vectors of human malaria parasites in Junin Department, Peru. J Am Mosq Control Assoc 3:418-422

50. Lima JB, Rosa-Freitas MG, Rodovalho CM, Santos F, Lourenco-de-Oliveira $\mathrm{R}$ (2014) Is there an efficient trap or collection method for sampling Anopheles darlingi and other malaria vectors that can describe the essential parameters affecting transmission dynamics as effectively as human landing catches? A review. Mem Inst Oswaldo Cruz 109:685-705

51. Hiwat H, De Rijk M, Andriessen R, Koenraadt CJ, Takken W (2011) Evaluation of methods for sampling the malaria vector Anopheles darlingi (Diptera, Culicidae) in Suriname and the relation with its biting behavior. J Med Entomol 48:1039-1046

52. Rubio-Palis Y, Moreno JE, Sanchez V, Estrada Y, Anaya W, Bevilacqua M et al (2012) Can mosquito magnet(R) substitute for human-landing catches to sample anopheline populations? Mem Inst Oswaldo Cruz 107:546-549

53. Gama RA, Silva IM, Geier M, Eiras AE (2013) Development of the BGMalaria trap as an alternative to human-landing catches for the capture of Anopheles darlingi. Mem Inst Oswaldo Cruz 108:763-771

54. Burkot TR, Russell TL, Reimer LJ, Bugoro H, Beebe NW, Cooper RD, Sukawati S, Collins FH, Lobo NF (2013) Barrier screens: a method to sample blood-fed and host-seeking exophilic mosquitoes. Malar J 12:49

\section{Submit your next manuscript to BioMed Central and take full advantage of:}

- Convenient online submission

- Thorough peer review

- No space constraints or color figure charges

- Immediate publication on acceptance

- Inclusion in PubMed, CAS, Scopus and Google Scholar

- Research which is freely available for redistribution

Submit your manuscript at

www.biomedcentral.com/submit

C Biomed Central 